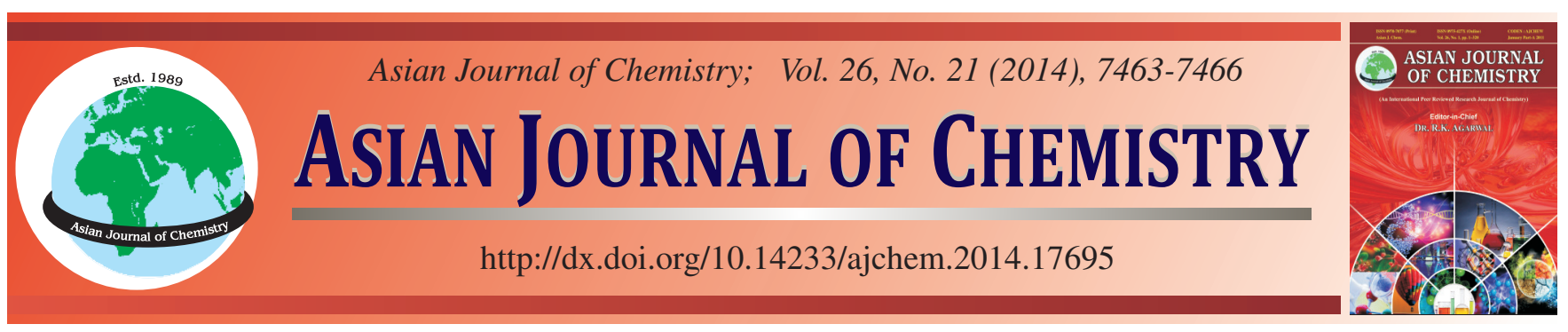

\title{
Synthesis, Characterization and Photocatalytic Behaviour of Cubic Structured Nanocrystalline Bismuth Titanate
}

\author{
Shih-Ween Yong ${ }^{1}$, Hartini Khairi Osman ${ }^{1}$, Siew-Teng Ong ${ }^{2}$, Sie-Tiong HA $^{2}$ and Siew-Ling Lee ${ }^{1, *}$
}

${ }^{1}$ Ibnu Sina Institute for Fundamental Science Studies, Universiti Teknologi Malaysia, 81310 Skudai, Johor, Malaysia

${ }^{2}$ Department of Chemical Science, Faculty of Science, Universiti Tunku Abdul Rahman, Jalan Universiti, Bandar Barat, 31900 Kampar, Perak, Malaysia

*Corresponding author: Fax: +60 7 5536080; Tel: +60 7 5536039, E-mail: sllee@ibnusina.utm.my

\begin{abstract}
New nanocrystalline bismuth titanate materials, $\mathrm{Bi}_{\mathrm{x}} \mathrm{TiO}_{1.5 \mathrm{x}+2}(\mathrm{x}=10,12,14,16$ and 18$)$ were successfully synthesized at $130{ }^{\circ} \mathrm{C}$. $\mathrm{X}$-ray powder diffraction analysis showed that these bismuth titanate materials formed a solid solution which crystallined in cubic crystal structure with $F m 3 m$ space group. The average particle size of these materials was $7.8 \mathrm{~nm}$. The increase of bismuth content caused a blue shift in the DR UV-visible spectra. More Bi-O-Ti bonds were detected in $\mathrm{Bi}_{10} \mathrm{TiO}_{17}$ compared to the other prepared materials as evidenced in the DR UV-visible analysis. Results demonstrated that the synthesized nanocrystalline bismuth titanate materials were potential photocatalysts in phenol degradation under ultraviolet light. Amongst, the nanocrystalline bismuth titanate with $\mathrm{Bi}_{10} \mathrm{TiO}_{17}$ has shown the highest phenol degradation.
\end{abstract}

Keywords: Nanocrystalline, Bismuth titanate, Cubic structured, Photocatalyst.

\section{INTRODUCTION}

Titania and titania-based materials have been widely studied due to their various potential applications ${ }^{1,2}$. In particular, bismuth titanate materials have received much attention for their high Curie temperatures, low optical activity, low dielectric constant and adequate active under ultaviolet light. Therefore, these materials are potentially used as ionic conductors, sensors, catalysts, photocatalysts etc. ${ }^{3,4}$. Several methods for synthesizing bismuth titanate such as coprecipitation, solid state reaction and hydrothermal synthesis have been reported ${ }^{4-6}$. However, these conventional methods have common drawbacks including high synthesis temperature and long synthesis duration, hence bringing into high cost of production. Moreover, the resulted materials were usually in micro size, making their performance in many applications was unsatisfied. Since it is widely accepted that nanostructured materials are better photocatalysts compared to materials at their micro size due to their larger surface area $a^{7,8}$, thus bismuth titanate materials in nano scale was highly desired.

The hot injection method appears as a relatively fast and economical method ${ }^{9}$. The precursors are usually quickly injected into a hot solvent to cause a rapid nucleation, followed by a subsequent growth of the nuclei at room temperature. Recently, we have reported on the synthesis of sillenite structured bismuth titanate via hot injection method accompanied by heating treatment at $600{ }^{\circ} \mathrm{C}^{10}$. The usage of nitric acid instead of non coordination solvent as reaction solvent has allowed the formation of nanocrystalline bismuth titanate at low temperature of $130{ }^{\circ} \mathrm{C}$. Here, nanocrystalline bismuth titanate materials of different compositions were synthesized via hot injection method without any heating treatment at higher temperature. Formation of new materials in cubic $\mathrm{Fm} 3 \mathrm{~m}$ structure and their photocatalytic activity was presented.

\section{EXPERIMENTAL}

Bismuth titanate was synthesized via the hot injection method as described elsewhere ${ }^{10}$. In this work, the mole ratio of bismuth to titanium was varied from 10:1 to 18:1. First, sufficient amount of bismuth nitrate (Aldrich 99.99\%) was dissolved in $2.5 \mathrm{~mL} 6 \mathrm{M}$ of $\mathrm{HNO}_{3}$ under vigorous stirring condition. After that, $10 \mathrm{~mL}$ of $\mathrm{N}, \mathrm{N}^{\prime}$-dimethyl formamide as stabilizer and oleic acid as surfactant were added dropwise into the solution. The mixture was stirred until an optical clear solution was obtained, followed by heating at $70{ }^{\circ} \mathrm{C}$ for 20 min. The solution was then heated to $130^{\circ} \mathrm{C}$ at where titanium butoxide (Sigma, $99 \%$ ) was injected into the hot mixture. The mixture was further heated at $130{ }^{\circ} \mathrm{C}$ for $2 \mathrm{~h}$ under stirring condition. Later, the hot plate was switched off and the mixture was left at room temperature for $24 \mathrm{~h}$ for crystallization process. Finally, the product was filtered and washed with 
hexane, continued by drying under vacuum condition. The resulted dry powder was submitted for characterization without any further heating treatment.

Phase identification of the resulted materials of different compositions was accomplished using powder X-ray diffraction (XRD) analysis employing a Siemens D5000. A scan rate of $0.05^{\circ}$ was applied to record the XRD pattern in $2 \theta$ range of $20-60^{\circ}$. The images of the materials were captured using JEOLJSM-6701F field emission scanning electron microscope (FESEM). The particle size of selected nanocrystallined bismuth titanate was measured using JEOL TEM 2100 transmission electron microscope (TEM). The exact values of bismuth and titanium in the material were analyzed by using inductively coupled plasma mass spectrometer (ICP-MS) Perkin Elmer 300 spectrometer. The Ti species formed was examined using a diffuse reflectance ultraviolet-visible (DR-UV-visible) Perkin Elmer Lambda 900 series spectrophotometer.

Detection method: The photocatalytic activity of the nanocrystalline bismuth titanate materials was evaluated through photodegradation of phenol under ultraviolet light using a 50 W VilberLourmat ultraviolet lamp. The reaction suspension was prepared by adding the prepared bismuth titanate into a $50 \mathrm{~mL}$ of $5 \mathrm{ppm}$ phenol solution. Before UV irradiation and testing, the suspensions were ultrasonically sonicated for 10 min followed by magnetically stirred in a dark condition for 90 min to establish adsorption or desorption equilibrium. The concentration of aqueous phenol was determined by measuring the absorbance at $270 \mathrm{~nm}$ with an UV-visible spectrophotometer, Perkin Elmer Lambda 900.

\section{RESULTS AND DISCUSSION}

All the synthesized bismuth titanate materials were in light beige color regardless the mole ratio ratios of bismuth to titanium used in the synthesis procedure. X-ray powder diffraction patterns of all the prepared materials were identical (Fig. 1) as no noticeable change in the peaks was observed. The results strongly implied these materials were having similar crystal structure. The identified peaks for the materials at $2 \theta=28.5$, $33.5,46.5$ and $55.5^{\circ}$ were matched well with that of reported $\mathrm{Bi}_{12} \mathrm{TiO}_{20}$ (PDF no: 42-186), suggesting these materials crystallined in cubic structure with $F m 3 m$ space group. The identical XRD patterns obtained for all the synthesized bismuth titanate materials were good indicator of solid solution formation in these materials. To our best of knowledge, this is the first time for a report on formation of solid solution of bismuth titanate materials crystallined in cubic structure. On the other hand, trace of impurities are found at $2 \theta=24.5$ and $42^{\circ}$. These impurities were believed to be formed from the reaction between oleic acid and $\mathrm{HNO}_{3}$ and they could be diminished ${ }^{10}$ at $400{ }^{\circ} \mathrm{C}$.

Fig. 2 shows FESEM images of the selected synthesized materials. As observed, the materials were aggregated and there was no significant difference in surface morphology among the materials. Observation under TEM suggested the particle size of these materials was independent to the bismuth and titanium compositions. Based on the measurement done using TEM, average of particle size of the synthesized bismuth titanate materials was $7.8 \mathrm{~nm}$ (Fig. 3), indicating nanocrystalline bismuth titanate was successfully synthesized.

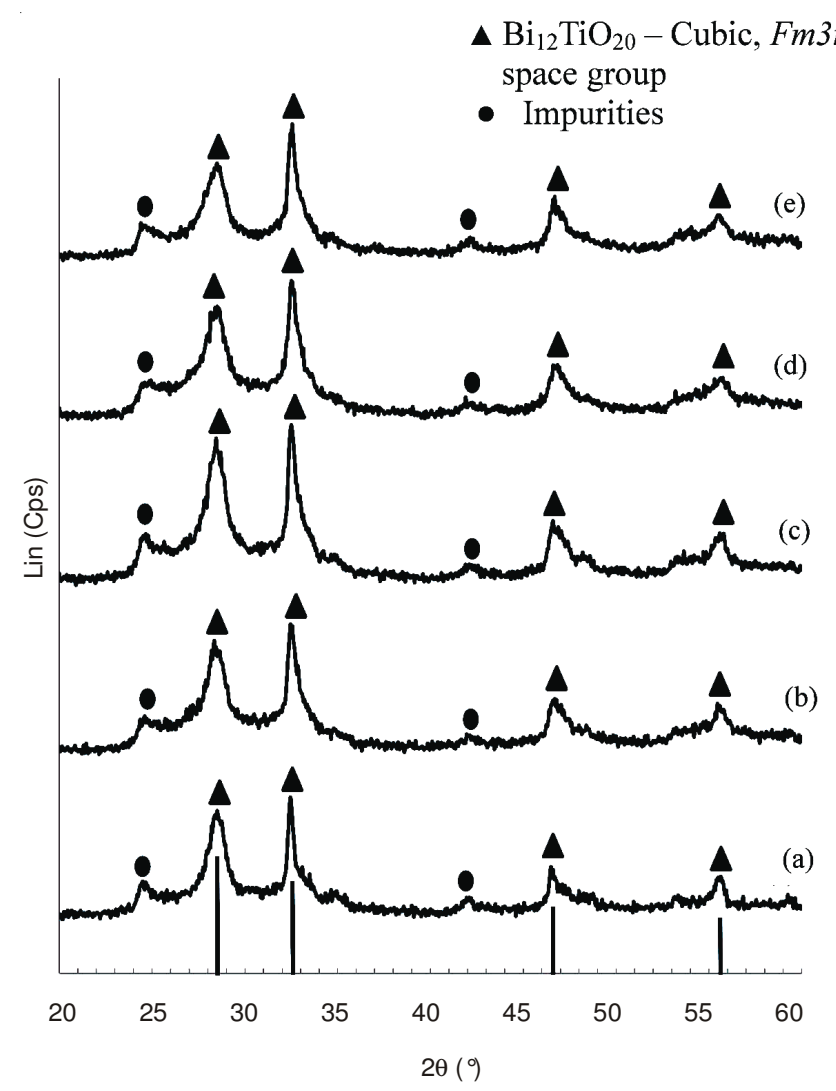

Fig. 1. XRD patterns of the sample synthesized via modified hot injection method (a) $\mathrm{Bi}_{10} \mathrm{TiO}_{17}$; (b) $\mathrm{Bi}_{12} \mathrm{TiO}_{20}$; (c) $\mathrm{Bi}_{14} \mathrm{TiO}_{23}$; (d) $\mathrm{Bi}_{16} \mathrm{TiO}_{26}$ and (e) $\mathrm{Bi}_{18} \mathrm{TiO}_{29}$ matching with the reported $\mathrm{Bi}_{12} \mathrm{TiO}_{20}$ (PDF no: 42-186)
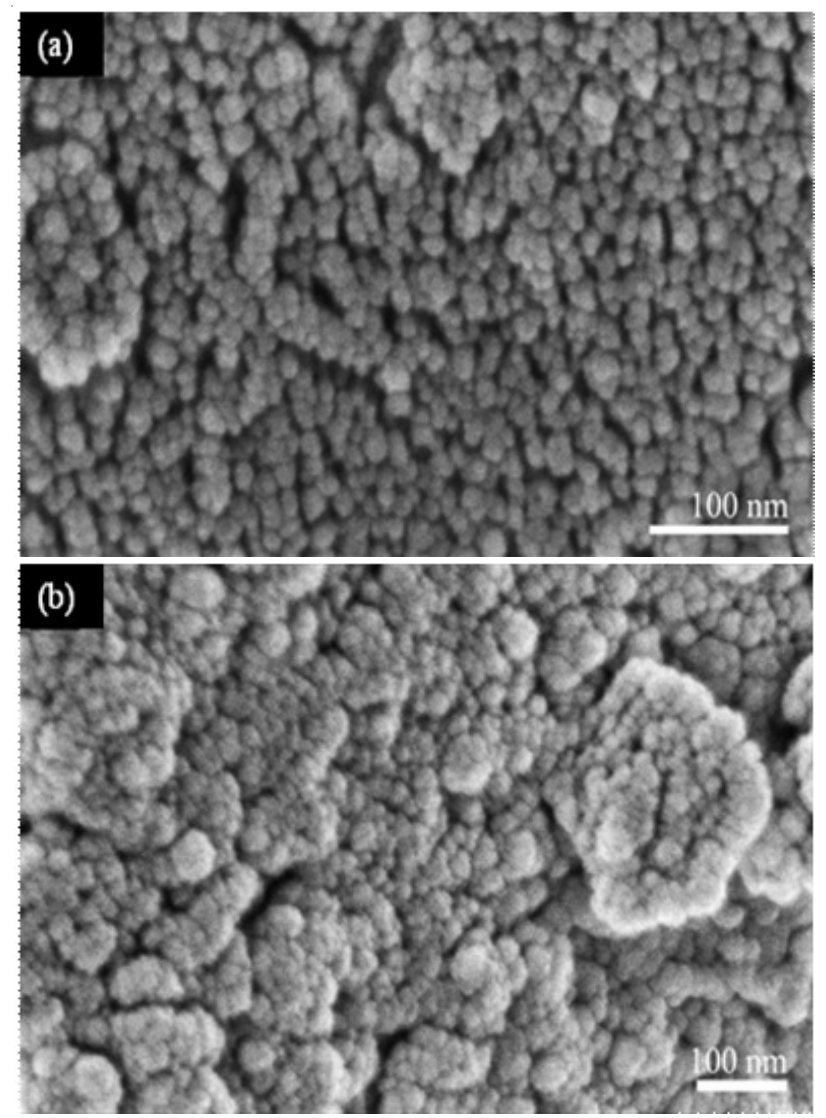

Fig. 2. FESEM micrographs showing surface morphology of the synthesized (a) $\mathrm{Bi}_{12} \mathrm{TiO}_{20}$ and (b) $\mathrm{Bi}_{18} \mathrm{TiO}_{29}$ 


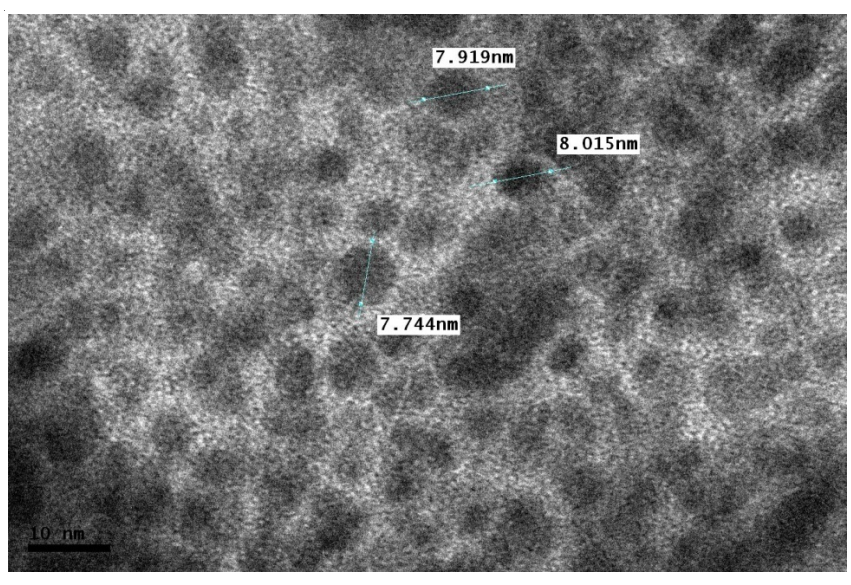

Fig. 3. TEM image showing particle size of $\mathrm{Bi}_{12} \mathrm{TiO}_{20}$

The exact amount of bismuth and titanium present in synthesized bismuth titanate materials was examined through ICP-MS (Table-1). Generally, the experimental values agreed with the theoretical values, thus confirming the compositions of the prepared materials. It was noticed that the actual amount of $\mathrm{Bi}$ species that found in the synthesized bismuth titanate was slightly lower (within $3 \%$ loss) than that of expected amount as from the calculated theoretical value. This could be due to the incomplete diffusion process and or possibly some $\mathrm{Bi}$ species which had reacted with the mixture of $\mathrm{HNO}_{3}$ and $\mathrm{N}, \mathrm{N}^{\prime}$-dimethylformamide during the injection of titanium species.

\begin{tabular}{ccc} 
TABLE-1 \\
THEORETICAL AND EXPERIMENTAL VALUES OF \\
MOLE RATIO OF Bi:Ti IN THE SYNTHESIZED \\
\multicolumn{3}{c}{ BISMUTH TITANATE MATERIALS } \\
\hline Material & $\begin{array}{c}\text { Theoretical value of } \\
\text { mol ratio of Bi:Ti }\end{array}$ & $\begin{array}{c}\text { Experimental value } \\
\text { of mole ratio of Bi:Ti }\end{array}$ \\
\hline $\mathrm{Bi}_{10} \mathrm{TiO}_{17}$ & $10: 1$ & $9.7 \pm 0.24: 1$ \\
$\mathrm{Bi}_{12} \mathrm{TiO}_{20}$ & $12: 1$ & $11.7 \pm 0.31: 1$ \\
$\mathrm{Bi}_{14} \mathrm{TiO}_{23}$ & $14: 1$ & $13.6 \pm 0.17: 1$ \\
$\mathrm{Bi}_{16} \mathrm{TiO}_{26}$ & $16: 1$ & $15.7 \pm 0.22: 1$ \\
$\mathrm{Bi}_{18} \mathrm{TiO}_{29}$ & $18: 1$ & $17.5 \pm 0.13: 1$ \\
\hline
\end{tabular}

The synthesized bismuth titanate materials were further analyzed using DR UV-visible spectroscopy. All of these materials showed an intense absorption band at $300 \mathrm{~nm}$ which is associated with Ti-O octahedral bonds (Fig. 4). Meanwhile, a weak shoulder at $260 \mathrm{~nm}$ attributed to Ti-O tetrahedral was observed. As can be seen, this shoulder became more intense with decreasing of $\mathrm{Ti}$ content in the materials, conforming formation of solid solution in these materials. On the other hand, presence of $\mathrm{Bi}-\mathrm{O}-\mathrm{Ti}$ bonds in the materials was detected by presence of absorption peaks at $380 \mathrm{~nm}$ and $515 \mathrm{~nm}$. These two peaks were weaken with reducing amount of $\mathrm{Ti}$ in the materials, indicating different ratio of $\mathrm{Bi}$ to Ti affected the type of $\mathrm{Bi}$ and $\mathrm{Ti}$ species formed without disturbing their crystal structure. Besides, the increasing of bismuth content had also caused a slight blue shift in the spectra. This phenomenon is good indicative for solid solution formation.

The band gap energies of the materials were calculated using Tauc plot which was plotted from the DR UV-visible spectra. The band gap energy of bismuth titanate crystallined

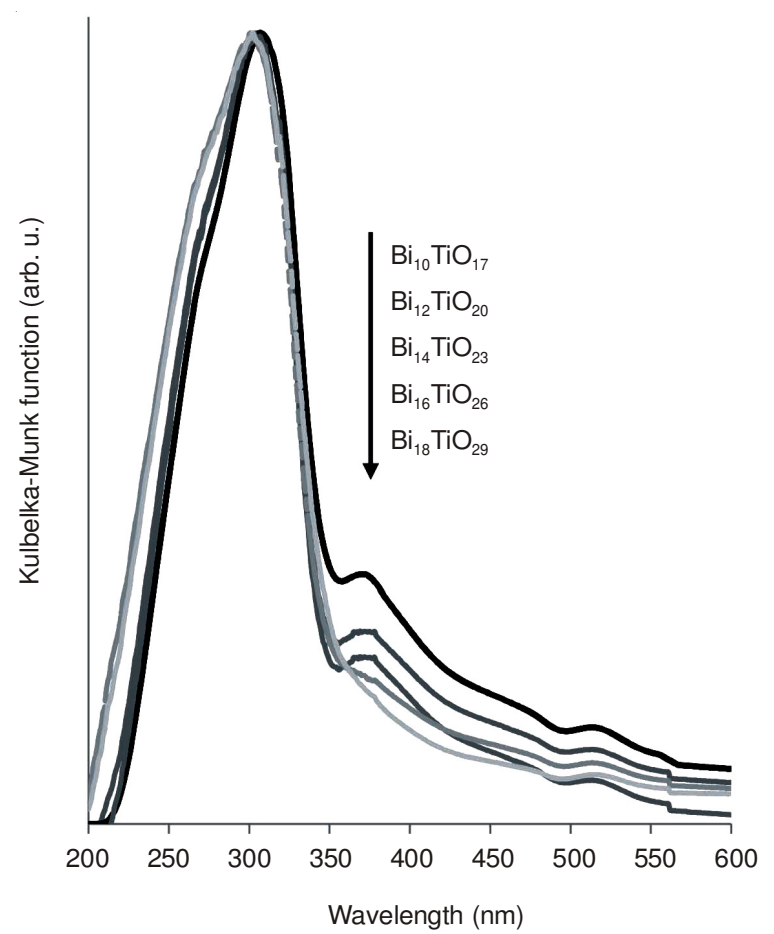

Fig. 4. DR UV-visible spectra of the synthesized nanocrystalline bismuth titanate materials

in Fm3m phase has not been reported. As shown in Table-2, band gap energies of the synthesized nanocrystalline bismuth titanate ranged from 3.52 to $3.63 \mathrm{eV}$. The band gap energy increased with the increasing of bismuth content in the materials. It was reported previously that the band gap energy for bismuth oxide varied from 2 to $3.96 \mathrm{eV}$ depending on the synthesis procedure and condition ${ }^{11}$. The high band gap energy of bismuth oxide was associated to the formation of conduction and valence bands from the delocalized $\mathrm{Bi} 6 \mathrm{p}$ and $\mathrm{O} 2 \mathrm{p}$ in the materials. Apparently, the band gap energies of the resulted materials were in the range of band gap energy of bismuth oxide. However, the values were slightly higher than that of $\mathrm{TiO}_{2}(3.20 \mathrm{eV})$.

TABLE-2

BAND GAP ENERGIES CALCULATED FROM TAUC PLOT OF THE NANOCRYSTALLINE BISMUTH TITANATE MATERIALS

\begin{tabular}{cc}
\hline Material & Band gap energy $(\mathrm{eV})$ \\
\hline $\mathrm{Bi}_{10} \mathrm{TiO}_{17}$ & 3.52 \\
$\mathrm{Bi}_{12} \mathrm{TiO}_{20}$ & 3.58 \\
$\mathrm{Bi}_{14} \mathrm{TiO}_{23}$ & 3.59 \\
$\mathrm{Bi}_{16} \mathrm{TiO}_{26}$ & 3.61 \\
$\mathrm{Bi}_{18} \mathrm{TiO}_{29}$ & 3.63 \\
\hline
\end{tabular}

The photocatalytic behavior of the new series of nanocrystalline bismuth titanate materials was examined through photodegradation of phenol under ultraviolet light. A blank experiment was conducted where phenol was irradiated with UV light without the presence of bismuth titanate materials. It was found that the concentration of phenol remained after $12 \mathrm{~h}$, indicating that there was no phenol degradation. Similarly, no change in phenol concentration in dark condition with the presence of bismuth titanate materials, suggesting the absorption of phenol on the surface of the compounds was negligible. 
As observed in Fig. 5, photodegradation of phenol increased significantly after illumination of ultraviolet light in the presence of bismuth titanate materials. For all materials, a steep increment was found at the first $2 \mathrm{~h}$ of reaction, followed by gradual increment. This could be associated with better diffusion at active sites at the beginning of the reaction. It was believed that attachment of reaction products on the surface of the photocatalysts may have retarded the further reaction at the active sites. Results showed the percentage degradation of phenol increased with decreasing of Bi content in the materials. The highest photodegradation of phenol of $88 \%$ was obtained by using nanocrystalline $\mathrm{Bi}_{10} \mathrm{TiO}_{17}$. Meanwhile, the lowest phenol photodegradation of $73 \%$ was found in the $\mathrm{Bi}_{18} \mathrm{TiO}_{29}$ catalyzed reaction. The high photodegradation was probably attributed to the higher percentage of titanium species located on the surface of the material in $\mathrm{Bi}_{10} \mathrm{TiO}_{17}$. It is well known that the titanium species acted as active sites for the photodegradation of organic compounds ${ }^{2}$. Therefore, the increased amount of Ti active sites on the surface of the materials has resulted in high photodegradation of phenol.

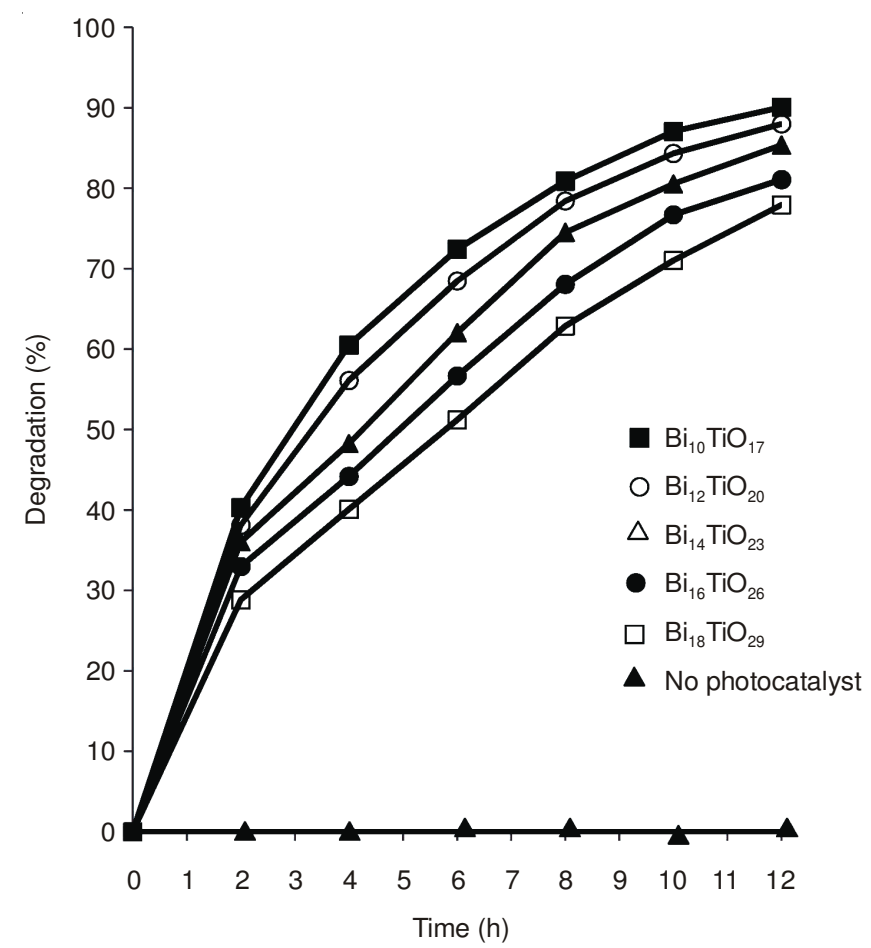

Fig. 5. Photocatalytic activity of different nanocrystalline bismuth titanate materials in degradation of phenol
The formation of more $\mathrm{Bi}-\mathrm{O}-\mathrm{Ti}$ bonding in $\mathrm{Bi}_{10} \mathrm{TiO}_{17}$ would have reduced the recombination rate of hole and electron generated from $\mathrm{Ti}$ active site, leading to the improved photocatalytic activity. It was believed that the Bi could act as electron scavenger effectively if it was located closely to the Ti species by forming Bi-O-Ti bonding in the photocatalyst ${ }^{12}$. Besides, the lower band gap energy of $3.52 \mathrm{eV}$ in $\mathrm{Bi}_{10} \mathrm{TiO}_{17}$ has also contributed to its good photocatalytic activity. Other than that, the possible end products after the photodegradation of phenol could be the intermediaries such as catechol, hydroquinone, lactic acid, acetic acid and formic acid ${ }^{13}$. These possible intermediaries are considered to be safe.

\section{Conclusion}

Nanocrystalline bismuth titanate materials of $\mathrm{Bi}_{\mathrm{x}} \mathrm{TiO}_{1.5 \mathrm{x}+2}$ $(\mathrm{x}=10,12,14,16$ and 18$)$ were successfully synthesized via modified hot injection method at low reaction temperature of $130{ }^{\circ} \mathrm{C}$. All of these new materials formed solid solution in cubic structure with $F m 3 m$ space group. The resulted materials of $\mathrm{Bi}_{\mathrm{x}} \mathrm{TiO}_{1.5 \mathrm{x}+2}(\mathrm{x}=10,12,14,16$ and 18) were potential photocatalysts for photodegradation of phenol.

\section{ACKNOWLEDGEMENTS}

Financial support of Research University Grant (research vote no.: Q.J.130000.2526.03H90) from the Ministry of Higher Education, Malaysia (MOHE) and Universiti Teknologi Malaysia is acknowledged.

\section{REFERENCES}

1. K.S. Beenakumari, J. Exp. Nanosci., 8, 203 (2013).

2. C. Guillard, J. Disdier, C. Monnet, J. Dussaud, S. Malato, J. Blanco, M.I. Maldonado and J.-M. Herrmann, Appl. Catal. B, 46, 319 (2003).

3. P.W. Koh, L. Yuliati and S.L. Lee, J. Teknologi, 69, 45 (2014).

4. J.J. Xu, M.D. Chen and D.G. Fu, Trans. Nonferrous Metals Soc. China, 21, 340 (2011).

5. K. Sardar and R.I. Walton, J. Solid State Chem., 189, 32 (2012).

6. J. Hou, S. Jiao, H. Zhu and R.V. Kumar, J. Solid State Chem., 184, 154 (2011).

7. Y. Hu, L. Fei, Y. Zhang, J. Yuan, Y. Wang and H. Gu, J. Nanomater., Article ID, 797639 (2011).

8. Y. Han, H. Kim and H. Kim, J. Nanomater., Article ID 427453 (2012).

9. L. Li, M. Protière and P. Reiss, Chem. Mater., 20, 2621 (2008).

10. S.W. Yong, H. Khairi Osman, P.W. Koh and S.L. Lee, Adv. Mater. Res., 287-290, 257 (2011).

11. T.P. Gujar, V.R. Shinde, C.D. Lokhande, R.S. Mane and S.H. Han, Appl. Surf. Sci., 250, 161 (2005).

12. H. Hamdan, M.N. Mohd Muhid, S.L. Lee and Y.Y. Tan, Int. J. Chem. Reactor Eng., 7, (2009).

13. C. Wu, X. Liu, D. Wei, J. Fan and L. Wang, Water Res., 35, 3927 (2001). 